\title{
Audit Risk and Rent Extraction: Evidence from a Randomized Evaluation in Brazil*
}

\author{
Yves Zamboni ${ }^{\dagger}$ \\ Stephan Litschig
}

February 13, 2012

\begin{abstract}
We report results from a randomized experiment designed and implemented by the Brazilian central government audit agency to test whether increased audit risk deters corruption and waste in local public procurement and improves provision of public services. We measure waste and corruption as irregularities in local public procurement and service delivery uncovered by central government auditors. Our estimates suggest that increasing audit risk by about 20 percentage points reduced the proportion of non-competitive procurement modalities adopted by local managers by about 17 percent. Higher audit risk also reduced the proportion of local procurement processes involving waste or corruption by about 20 percent. In contrast, we find no evidence that increased audit risk affected the quality of publicly provided preventive and primary health care services, measured using client satisfaction surveys. We also find no evidence that higher audit risk had an effect on local compliance with national guidelines of the conditional cash transfer program Bolsa Familia, measured in terms of appropriate inclusion of beneficiaries into the program or their compliance with health and education conditionalities.
\end{abstract}

Keywords: Corruption, Rents, Local Governments, Law Enforcement JEL: D73, D78, H41, H83, K42

\footnotetext{
*We are grateful for comments from Antonio Ciccone, Patricia Funk, Scott Desposato, Miguel de Figueiredo, Jorge Hage, Maksym Ivanyna, George Musser Jr., Luiz Navarro and from seminar participants at the Fiscal Federalism Workshop at IEB in Barcelona and the Political Economy Workshop at Erasmus University in Rotterdam. The views expressed in this paper are those of the authors and not necessarily those of the Controladoria-Geral da União. All errors are our own.

†Fundação Getulio Vargas São Paulo, yves.zamboni@gmail.com.

†Universitat Pompeu Fabra and Barcelona GSE, stephan.litschig@upf.edu.
} 


\section{Introduction}

Waste and corruption are two key determinants of the cost of public service provision. Keeping waste and corruption - rent extraction for short-low is important in its own right and is also widely believed to be a driver of economic development (Rose-Ackermann 1999, 2004). However, measuring rent extraction objectively is notoriously challenging. ${ }^{1}$ It is even more challenging to assess whether rent extraction is responsive to policy intervention because topdown monitoring policies in particular are only rarely truly or "as if" randomly assigned.

In this paper we report results from a randomized evaluation designed to test whether higher audit risk deters corruption and waste in local public procurement and improves provision of public services in Brazil. Following the economic approach to crime (Becker 1968), an official will shirk or steal if and only if the expected utility from doing so exceeds utility under the person's best alternative. Expected utility depends on the magnitude of sanctions if caught and the probability of their application. While higher audit risk should lower the expected utility from shirking or stealing and hence deter rent extraction, the magnitude of this effect depends on the probability that sanctions are applied conditional on detection. In the Brazilian setting analyzed here, as in many other countries, the probability that local officials are punished through fines, loss of mandate or prison time is typically considered to be very low (Arantes 2004). To what extent higher audit risk deters waste and corruption in such environments is therefore an open and important empirical question.

Our research design relies on the randomization of 120 municipalities into a treatment group, exposed to a roughly 20 percentage points higher annual probability of being audited than the $5 \%$ audit probability in the control group, effectively consisting of the 5'400 remaining municipalities in Brazil. ${ }^{2}$ The randomization was designed by the Brazilian federal government internal audit agency (Controladoria-Geral da União, CGU) and carried out and publicly an-

\footnotetext{
${ }^{1}$ Di Tella and Schargrodski (2003) look at prices paid by hospitals for basic supplies before and after a crackdown on corruption. Reinikka and Svensson (2004) examine the difference between funds disbursed by the central government and funds reportedly recieved by schools. Golden and Picci (2005) compare physical public infrastructure to the cumulative amount of government spending on that infrastructure. Olken (2007) computes "missing" expenditures in road construction using independent cost estimates provided by engineers. Ferraz and Finan (2010) construct corruption measures based on audit findings. Litschig and Zamboni (2010) also use audit results to measure rents, but without distinguishing between waste and corruption.

${ }^{2}$ Municipalities are the lowest level of government in Brazil (below the federal and state governments).
} 
nounced in May 2009. ${ }^{3}$ In order to ensure that municipalities were aware of their treatment status, mayors in treatment group municipalities also received a letter from CGU, stating that they were part of a group of 120 municipalities, 30 out of which would be audited one year later. ${ }^{4}$ In May 2010, CGU sampled 30 treatment as well as 30 control municipalities as part of the regular random auditing process. From May 2010 onwards, treatment group municipalities were again exposed to a roughly $5 \%$ annual audit probability. ${ }^{5}$ The treatment thus consisted of a temporary increase in audit risk of about 20 percentage points.

We measure waste and corruption as irregularities in local public procurement and service delivery uncovered by CGU auditors. If compliance with homogeneous national regulations is socially beneficial, irregularities in procurement or service delivery uncovered by auditors provide an objective measure of rent extraction by local executive officials, either through outright corruption or low effort on the job. ${ }^{6}$ For the vast majority of the regulations considered by auditors in Brazil, compliance is likely to be socially beneficial although typically privately costly. ${ }^{7}$ For example, procurement regulations are designed to ensure that the public pays the lowest price available for a given good or service required, yet implementing a competitive procurement procedure, such as a (reverse) auction, is privately costly for the local manager. Similarly, health ministry regulations require medical staff to provide certain service hours, which is again privately costly, yet beneficial for service users.

We focus on irregularities overall, rather than one particular type of rent extraction such as corruption. Our reasons for doing so are twofold. First, irregularities are based on objectively verifiable facts, while identification of proper corruption episodes inevitably requires judgment since few cases are clear-cut in practice. CGU auditors themselves explicitly abstain from making such judgments and leave it to prosecutors to decide whether to further investigate certain irregularities and potentially press charges against particular individuals. Our second

\footnotetext{
${ }^{3}$ We introduced the idea of conducting a randomized evaluation to CGU staff and were involved in the early design stage of the project.

${ }^{4}$ This implies that we cannot disentangle the effect of simply receiving a letter from CGU from the effect of exposure to a higher audit probability. However, the effect of the letter "treatment" is likely to be orders of magnitude smaller than the effect of exposure to an objectively higher audit risk.

${ }^{5}$ Treatment group municipalities were thus never exposed to lower audit risk than those in the control group.

${ }^{6}$ Effort can be seen as negative rents as in Barro (1973) and Persson and Tabellini (2000).

${ }^{7}$ In the terminology of Bandiera, Prat and Valletti (2009) we think of irregularities uncovered by auditors as a measure of active waste in government spending: compliance is socially beneficial yet privately costly.
} 
reason for focusing on overall irregularities is that the law is not limited to penalizing corruption, which requires a relatively high standard of proof because individuals can go to jail if convicted, but allows prosecutors to charge individuals with the lesser offense of "acts of administrative misconduct". Since higher audit risk should operate on both corruption and administrative misconduct, a comprehensive measure of rents is more appropriate for our purposes. ${ }^{8}$

In order to increase sample size, we supplement the 60 municipalities sampled for an audit in May 2010 with 60 control group municipalities that were sampled two months earlier in March 2010. ${ }^{9}$ Our procurement data span the entire range of locally provided public services in Brazil, including preventive and primary health care, elementary education, housing and urban infrastructure, and transportation. In addition, we use survey data collected by auditors to assess the quality of preventive and primary health care services under a nation-wide program (Saúde da Família) and to assess local compliance with national guidelines of the conditional cash transfer program (Bolsa Família). ${ }^{10}$

Our main empirical results provide clear evidence in favor of the prediction that local officials reduce rent extraction in response to higher audit risk. Our estimates suggest that increasing audit risk by about 20 percentage points reduced the proportion of non-competitive procurement modalities adopted by local managers by about 17 percent. Higher audit risk also reduced the proportion of local procurement processes involving waste or corruption by about 20 percent. Whether these effects reflect a net reduction in rent extraction or merely a substitution over time- - with treatment group municipalities "making up" at least some lost rents in subsequent periods - we cannot say. In either case, however, the results provide strong empirical support for the economic approach to crime (Becker 1968).

In contrast, we find no evidence that increased audit risk affected the quality of preventive and primary health care services provided under the Saúde da Familia program, measured using client satisfaction surveys. Since potential punishments for serious irregularities in procurement

\footnotetext{
${ }^{8}$ We could, of course, attempt to code corruption as an additional outcome measure if required.

${ }^{9}$ Our relatively small sample size also precludes meaningful subgroup analysis. We have investigated, for example, whether higher audit risk has a different effect on rent extraction for first- or second-term mayors and found no significant difference there. Results are available on requrest.

${ }^{10}$ There are other major programs, in education for example, as well as programs and projects that run only in a subset of municipalities, for which we do not have the audits data.
} 
include jail, while for service delivery they only include fines or loss of the job, differences in potential punishments might drive the difference in results. A complementary interpretation is that irregularities in service provision cannot be identified with the same precision as irregularities in procurement and so higher audit risk might matter less to service providers, compared to procurement officials. Irregularities in procurement are relatively easy to identify because local officials are required to document each step of the process. In contrast, the behavior of local service providers is much harder to verify through a CGU audit. For example, while health facility users might complain about infrequent opening hours of the health post, health staffers could easily dispute this fact and auditors would have a hard time verifying any of these competing claims.

We also find no evidence that higher audit risk had an effect on local compliance with national guidelines of the conditional cash transfer program Bolsa Familia, measured in terms of appropriate inclusion of beneficiaries into the program or their compliance with health and education conditionalities. Again, differences in punishment are likely to be part of the explanation for the zero effect since the punishment for overstating the number of kids in the household or for not sending them to school, for example, is at most the loss of the benefit. Another interpretation, which is supported by our data, is that most Bolsa Familia recipients were appropriately included in the program - they were poor enough — and they already complied with health and education conditionalities to a large extent. ${ }^{11}$ Thus, they could not respond to higher audit risk because they were doing nothing wrong in the first place.

To our knowledge the only antecedent to our study using a (field) experimental research design is Olken (2007), who examines the effect of a higher audit probability on corruption in road construction in Indonesia. He finds that an increased probability of a government audit, from a baseline of 4 percent to 100 percent, reduces "missing" expenditures by 8 percentage points relative to total project expenditures. As in our case, Olken's research design essentially evaluates the effect of a temporary (and project-specific) increase in audit risk. Compared to the proportion of non-competitive procurement modalities and the proportion of local procurement processes involving waste or corruption used in our study, Olken's measure of corruption is

\footnotetext{
${ }^{11}$ Compliance with education and health conditionalities might of course be overstated by local officials.
} 
clearly more precise. The advantages of our outcomes are that they measure rents more broadly, encompassing both waste and corruption, and that they are available for government procurement across the entire range of locally provided public services, not just for road construction. Moreover, our survey data also allow us to go beyond input measures, such as "missing" expenditures, and examine potential effects on outputs, such as quality of public services.

The paper is organized as follows. In Section 2 we describe the audits program and give institutional background on the enforcement of public sector regulations in Brazil. Section 3 presents theoretical predictions regarding the effect of higher audit risk on shirking or stealing by local officials. We discuss the experimental design and our estimation approach in Section 4. In Section 5 we present the data on irregularities in local public procurement and service delivery. Estimation results are presented in Section 6. We conclude with a discussion of limitations and extensions.

\section{Audits program and institutional background}

\subsection{The random audits program}

The random audits program was initiated under the government of Luiz Inácio Lula da Silva in March 2003 with the explicit objective of fighting corruption and waste in local public spending. Most municipalities were eligible for federal audit from the start of the program with the exception of state capitals. ${ }^{12}$ Several rounds of sampling occur each year through a public lottery. The machinery used for the selection of municipalities is the same as that used for a popular national (money) lottery and results are broadcast on television and through other media. As of July 2010, 33 rounds have been carried out with 60 municipalities sampled in recent rounds. Sampling is geographically stratified by state and there is no doubt that the sampling is truly random.

The program is implemented by the general comptroller's office (CGU), the internal audit institution of the federal government. When a municipality is selected, the CGU headquarters in Brasilia determines the specific aspects of programs and projects that are audited and issues de-

\footnotetext{
${ }^{12}$ More specifically, eligibility for federal audit is based on a population threshold which was successively increased from 20 '000 to 500 '000.
} 
tailed inspection orders (ordens de serviço) — standardized sets of program- or project-specific inspections - to state CGU branches. For simplicity we will usually refer to service orders as inspections, although technically service orders are sets of inspections. Teams of auditors that are based in these state branches are then sent to the sampled municipality. Transfers eligible for audit include those that are earmarked to carry out national health and education policies (legais), direct transfers to citizens (diretas), as well as other negotiated transfers (voluntarias), but exclude revenue-sharing transfers, such as those from the Fundo de Participação dos Municípios. Inspections occur for a subset of eligible federal transfers made during the preceding two to three years. ${ }^{13}$

The number of auditors dispatched depends on municipality size (area and population), the proportion of rural and urban areas and the number of inspection orders, which in turn depends on the number of programs and projects running in the municipality. For instance, a municipality with a small population and a low number of items to be checked, but with a large rural area may require more auditors than another municipality with larger population but more people living in urban areas. In addition, municipalities for which the CGU has received a lot of complaints or where the mayor was recently impeached, receive larger teams.

Within a week of the municipality sampling, auditors spend about two weeks in the municipality in order to carry out their inspection orders. The quality of public services is assessed through interviews with the local population and service staff members. Auditors then write a report which details all the irregularities encountered during their mission. Reports include the amounts of resources audited, and if possible, any fraction that was diverted, wasted or stolen. This fraction is just a preliminary estimate, however. The exact amount diverted can only be assessed through a more detailed inspection which occurs only if it is subsequently deemed appropriate by the prosecutor in charge of the municipality. Municipality mayors are given the possibility to comment on the draft report within five business days. Auditors in turn explain whether or not they accept the mayor's justification of problems found.

\footnotetext{
${ }^{13}$ Exceptions to this rule are possible if warranted by the program under inspection.
} 


\subsection{The enforcement of public sector regulations}

Final audit reports are sent to local legislatures, the federal ministries which are remitting the transfers, external audit institutions at state and federal levels, as well as state and federal prosecutors. Prosecutors then decide whether to further investigate the irregularities uncovered by auditors and whether and what charges to press against particular individuals. If convicted of corruption, defendants may be imprisoned for 1 to 8 years, in addition to losing their mandate and incurring fines. If convicted of "acts of administrative misconduct" or "improbity", punishments include the loss of mandate, the suspension of political rights for 8 to 10 years, prohibition from entering into public contracts for 10 years as well as the obligation to reimburse public coffers. $^{14}$

\section{Theoretical predictions}

Following the economic approach to crime, an official will shirk or steal if and only if the expected utility from doing so exceeds utility under the person's best alternative. Expected utility depends on the magnitude of sanctions if caught and the probability of their application. Using Becker's (1968) notation, let $Y$ denote the income or monetary equivalent of committing an irregularity, $f$ the fine or monetary equivalent of the punishment, $p$ the probability that the punishment is applied and $U_{i}(Y)$ person $i$ 's utility function, which is assumed increasing in $Y$. The expected utility from shirking or stealing is then as follows:

$$
E\left(U_{i}\right)=p U_{i}(Y-f)+(1-p) U_{i}(Y)
$$

In this simple framework, the person will shirk or steal if and only if $E\left(U_{i}\right) \geq \mu_{i}$, where $\mu_{i}$ denotes $i$ 's best alternative. It is clear that if higher audit risk increases $p$ - thereby lowering the expected utility from shirking or stealing-some people will be deterred from committing an irregularity:

$$
\frac{\partial E\left(U_{i}\right)}{\partial p}=U_{i}(Y-f)-U_{i}(Y)<0
$$

\footnotetext{
${ }^{14}$ See Arantes (2004) on the organization and legal instruments at the disposal of the Brazilian "Ministerio Publico".
} 
But the magnitude of this effect depends on the probability that sanctions are applied conditional on being audited. Let $p_{c}$ denote the probability of sanctions conditional on receiving an audit and $p_{a}$ the probability of a central government audit, so that $p=p_{c} \times p_{a}{ }^{15}$ Then:

$$
\frac{\partial E\left(U_{i}\right)}{\partial p_{a}}=p_{c}\left[U_{i}(Y-f)-U_{i}(Y)\right]<0
$$

This equation makes it clear that the same variation in audit risk affects expected utility differently, depending on the probability that sanctions are applied conditional on being audited and depending on the severity of sanctions. Specifically, the predicted reduction of irregularities due to higher audit risk is stronger, the more likely it is that sanctions are applied conditional on detection and the more severe the punishment. Since in our case potential punishments for serious irregularities in procurement include jail, while for service delivery they only include fines or loss of the job, the economic approach to crime provides a simple interpretation of our differential results for procurement and service delivery. A complementary interpretation is that irregularities in service provision cannot be identified with the same precision as irregularities in procurement $-p_{c}$ is likely lower in service delivery-and so higher audit risk should matter less to service providers, compared to procurement officials.

\section{Experimental design}

The randomization was designed by the Brazilian federal government internal audit agency (Controladoria-Geral da União, CGU) and carried out on May 12th 2009. The machinery used for the selection of treatment group municipalities was the same as that used for regular CGU audits and the results were later broadcast on television and through other media. The randomization of 120 municipalities into the treatment group was stratified by state as shown in Table 1. At the time of the randomization it was publicly announced that out of the 120 municipalities in the treatment group, 30 would be sampled for a regular CGU audit one year later in May 2010. ${ }^{16}$ It was also announced that the 120 municipalities in the treatment group were not eligible for regular CGU audits until May 2010, while the control group, consisting

\footnotetext{
${ }^{15}$ For simplicity we assume that the probability of detection of the irregularity conditional on being audited is 1.

${ }^{16}$ Portaria N. ${ }^{o}$ 930, May 8th 2009.
} 
of the remaining 5'400 municipalities, could be sampled during regular lotteries as usual. ${ }^{17}$ In order to ensure that municipalities were aware of their treatment status, mayors in treatment group municipalities also received a letter from CGU containing the above information.

While the initially announced (ex ante) probability of an audit for treatment group municipalities was thus $25 \%$, the corresponding annual audit risk for control municipalities depended on the number of lotteries and the probability of being sampled in each of these. From May 2009 to May 2010 there were four regular lotteries, namely the 29th, 30th, 31st and 32nd, as illustrated in Figure 1. Table 2 presents the audit probabilities that municipalities from different states faced in the 29th lottery. For most states, audit probabilities per round of the lottery are about 1 or 2 percent. These probabilities were essentially unchanged from previous rounds and remained as such for subsequent lotteries.

In the 32nd regular lottery, the details of which were announced on April 30th 2010, 30 municipalities were drawn from the treatment group and 30 from the control group. ${ }^{18}$ Table 3 shows that, because sampling in both groups was stratified by state, ex post audit probabilities in the treatment group varied between $16.7 \%$ and $50 \%$, with a modal probability of $25 \%$. Since the details of the actual sampling scheme used in May 2010 were unknown to the public until a few days before the 32 nd lottery, the relevant audit risk for treatment group municipalities that could have affected the behavior of local officials likely was $25 \%$.

The corresponding annual audit risk for control municipalities can be approximated as follows:

$$
\begin{aligned}
P(\text { Audit } \mid \text { Control }) & =1-P(\text { No Audit in any of lotteries } 29 \text { through } 32) \\
& =1-[1-P(\text { Draw } 29 \text { th })]^{3} \times[1-P(\text { Draw } 32 \text { nd })]
\end{aligned}
$$

Table 3 shows that annual audit probabilities in the control group fell mostly in the range of 3 to 6 percent. Ex ante, that is from May 12th 2009 to April 30th 2010, treatment group municipalities were thus exposed to a roughly 20 percentage points higher annual probability

\footnotetext{
${ }^{17}$ As mentioned above, state capitals and municipalities with population size above 500'000 are exempt from the random audits program. A few other municipalities had received special audits recently and were also exempt from the experiment (Portaria N. ${ }^{o}$ 930, May 8th 2009).

${ }^{18}$ Portaria N. ${ }^{o} 862$, April 30th 2010.
} 
of being audited than the treatment group municipalities.

\subsection{Estimation approach}

Given the experimental design, estimation is a straightforward comparison of sample mean outcomes from treatment and comparison groups. Let $Y_{m}$ denote the outcome variable in municipality $m, \beta_{m}$ the (heterogeneous) treatment effect, $D_{m}$ the treatment indicator and $U_{m}$ other unobserved factors that affect the outcome. The data generating process can then be described as:

$$
Y_{m}=\alpha+\beta_{m} D_{m}+U_{m}
$$

Randomization ensures that, in expectation, $D_{m}$ is uncorrelated with $U_{m}$, so $\widehat{\beta}^{O L S}$ provides an unbiased and consistent estimator of the average treatment effect $E\left(\beta_{m}\right)$. Since treatment probabilities vary somewhat by state due to the conditional randomization, we also present specifications with state fixed effects $c_{S}$. We also provide a check on small sample bias by including pre-treatment municipality characteristics and mayor's characteristics, such as age, gender and education, as well as the mayor's party affiliation $W_{m}$ into the regression. Finally, we present results separately for the sample from the 32nd lottery and for the pooled sample including the 31 st lottery, which we add to increase the precision of our estimates. It is worth emphasizing that including municipalities from the 31 st lottery might lead to bias if outcomes were systematically different from one year to the next. Fortunately this turns out not to be the case as evidenced by the fact that point estimates vary only slightly across the $32 \mathrm{nd}$ and pooled estimation samples.

\section{Data}

Having described some key features of the Brazilian control system and the experimental design, we now present our micro-data on irregularities in local public procurement and public service delivery in more detail. Our empirical analysis is based on a random sample of $60+60$ municipalities that have been audited in March and May 2010, respectively. Audit findings for each municipality were compiled into a database by CGU staff. Following the practice of the 
comptroller general's office, we refer to the reported infractions of public sector management regulations as irregularities in public administration. It is worth emphasizing that each reported irregularity constitutes a breach of a specific legal norm by a local official or service provider and is potentially subject to prosecution by state procuracies.

\subsection{Local public procurement data}

Our procurement data are at the level of individual procurement processes and cover all purchases made with federal funds during the audit period, from January 2009 to May 2010 for the 32nd lottery and from January 2008 to December 2009 for the 31 st lottery as illustrated in Figure $1 .{ }^{19}$ The procurement data span the entire range of locally provided public services in Brazil, including preventive and primary health care, elementary education, housing and urban infrastructure, and transportation.

Table 4 presents the distribution of goods and services purchased by local governments in our sample. The unit of observation is an individual procurement process. Staple foods, used for a public school meal program, for example, are the most frequently acquired items. Other commonly purchased items are medications for the basic health care program, as well as other non-durable goods. Public works and contracted-out services also constitute a large fraction of local public procurements. Table 4 also shows that there are no obvious differences between treatment and control municipalities in terms of the types of goods and services bought, nor are there difference between control municipalities from the 31 st and 32 nd lotteries.

Table 5 presents the distribution of procurement modalities by treatment status. The unit of observation is again an individual procurement process. There are six modalities in total, three of which restrict the number of competitors and are legal only below certain purchase amounts, and another three modalities without restrictions on the number of competitors. ${ }^{20}$ We refer to non-competitive procurement modalities as direct purchases by the local administration, "bids only by invitation" (convite), a modality which leaves it at the total discretion of the local

\footnotetext{
${ }^{19}$ Because the date of each procurement process is not given in our data, only the year, we cannot exclude processes that were completed prior to May 2009. The inclusion of these processes - which could not have been affected by higher audit risk by construction - will bias our estimates towards zero.

${ }^{20}$ This distinction between procurement procedures that are open to all interested suppliers and those that are not is made in the Agreement on Government Procurement in Article VII.3. Brazil is not formally a member of the treaty.
} 
administration whom to "invite", ${ }^{21}$ and the modality "only pre-registered bidders" (tomada de preços), which restricts competition to pre-registered suppliers. ${ }^{22}$ Competitive modalities are the "sealed-bid (reverse) auction" (concorrência), "on-site (reverse) auction" (pregão presencial) and "electronic (reverse) auction" (pregão eletrõnico).

A noteworthy feature of the data is that in the control group from the 32nd lottery, there were 187 procurement processes of the non-competitive modality "bids only by invitation", but there were only 97 processes using this modality in the treatment group. Similarly, of the modality "only pre-registered bidders", there were 65 processes in this control group but only 44 of them in the treatment group. For the remaining and more competitive modalities, "sealed-bid (reverse) auction", "on-site (reverse) auction" and "electronic (reverse) auction", the numbers of processes in treatment and control groups are essentially equal. It is also interesting to note that there are no real differences in the proportions of procurement modalities between control municipalities from the 31 st and 32nd lotteries, suggesting that pooling across lotteries is appropriate. For estimation purposes, we compute municipality-level proportions of noncompetitive modalities across treatment and control groups.

Table 6 presents the distribution of audit results for procurement by treatment status. Several features of the data stand out. First, the share of irregular processes, that is, those that were found to be non-compliant with procurement regulations in one way or another is about 0.72 and 0.71 in the control groups from the 32nd and 31st lotteries, respectively, but only about 0.54 in the treatment group. Common examples of irregular processes, given in Table 6, are fractionalizing, that is, division of a purchase into smaller amounts in order to avoid more competitive modalities or favoritism, that is, evidence that the contract was steered towards certain suppliers.

Second, the share of processes that show evidence of fractionalizing is about $4 \%$ in the treatment group but about $12 \%$ and $8.5 \%$ in the control groups from the $32 \mathrm{nd}$ and 31 st lotteries, respectively. This is consistent with the observation above that the number of non-competitive

\footnotetext{
${ }^{21}$ This corresponds to a limited tendering procedure under the Agreement on Government Procurement, Article VII:3(c).

${ }^{22}$ This corresponds to a selective tendering procedure under the Agreement on Government Procurement, Article VII:3(b).
} 
procurement processes is higher in the control group.

Third, a comparison of audit findings across control municipalities from the 31 st and 32 nd lotteries reveals that the proportions are very similar for the majority of procurement processes, except for the incidence of favoritism, simulated processes and other irregularities. It appears in particular that in the 32nd lottery, irregularities coded previously as instances of favoritism were now coded either as simulated processes or other irregularities. Since we are primarily interested in measuring compliance with procurement regulations, rather than distinguishing among cases of non-compliance, these differences are without consequence for our study. The important fact is that the share of irregular procurement processes in the two control groups is almost identical, $72 \%$ for the $32 \mathrm{nd}$ and $71 \%$ for the 31 st lottery, respectively, while the irregular share in the treatment group is $54 \%$. For estimation purposes we aggregate the micro-data on audit findings in procurement to the municipality level and compare the proportion of irregular processes across treatment and control groups.

\subsection{Survey data}

As part of their standard service orders, CGU auditors conduct interviews and field visits that are designed to assess public service quality at both the household and service-unit level. For the preventive and basic health care program (Saúde da Família), auditors first check the compliance of service units with ministry of health guidelines, for example regarding adequacy of the number of service personnel for their assigned service area and adequacy of the team composition (e.g. one doctor, one nurse, 12 technical assistants). Auditors then sample households at random from locally provided sampling frames of service users. In our data, the auditors interviewed 22 families on average per municipality in order to assess whether respondents receive adequate quality of care. For example, auditors ask whether the family receives regular visits from community health workers and whether care is provided at the health post if needed.

For the conditional cash transfer program (Bolsa Família), CGU headquarters provides auditors in the field with a list of typically 30 randomly sampled transfer recipient households based on a national sampling frame. ${ }^{23}$ Auditors conduct field visits to check whether trans-

\footnotetext{
${ }^{23}$ The exact number of respondents can vary depending on conditions in the field.
} 
fer recipient families are of a size and income level compatible with program guidelines and whether children's vaccinations are done regularly as required under the program. Auditors also check school records to assess compliance with enrollment and attendance conditionalities for obtaining the cash transfer.

Most of the survey responses are either yes, no, or not applicable, if the household required no health services over the preceding year, for example. In the empirical analysis below we aggregate the household-level data to the municipality level by computing the share that responded yes to a particular question out of the total of respondents who responded either yes or no.

\subsection{Caveats}

There are three caveats worth pointing out regarding our measures of rent extraction. ${ }^{24}$ First, we assume that existing regulations on procurement and service delivery — which define irregularitiesmake sense, that is, they serve a legitimate purpose in a reasonable way. ${ }^{25}$ Put differently, we take irregularities to be generally detrimental to public service delivery, rather than reflecting attempts by well-meaning officials to circumvent inefficient red tape. As mentioned above, mayors, managers and service providers have the possibility to comment on the audit report. Sometimes auditors concede that there are valid arguments for non-compliance and we exclude these instances from our measures. Based on our reading of the regulations considered here, we believe that reported irregularities are for the most part undesirable from a social point of view because they either involve a direct waste or loss of public resources or complicate the detection of such mismanagement. It is also worth noting that the regulations pertaining to public procurement reflect international best practices as laid out in the WTO's Agreement on Government Procurement.

The second caveat is that we need to assume that auditors themselves were not bribed into manipulating audit findings (Mookherjee and Png, 1995). If this manipulation were for some reason correlated with treatment status, it would bias our estimates. However, we believe that

\footnotetext{
${ }^{24}$ Only the first caveat is genuine to our study. The other two apply to measures of waste and corruption more generally.

${ }^{25}$ Without this assumption we are still evaluating compliance with existing regulations.
} 
the institutional setup makes it very unlikely that auditors are corrupt. First, auditors are paid by the federal government, not by local governments, which makes it less likely that they are captured by local special interests. Second, auditors work in teams of about 10 people. This makes it hard to sustain collusion on any significant scale because the whole team has to be bribed in order to conceal irregularities. Third, the interaction between auditors and local officials is at a single point in time (unknown ex ante), which again makes it harder to sustain collusion.

The third caveat is that even if auditors were incorruptible, the local elite might somehow manage to manipulate what gets uncovered and what remains unnoticed. While this scenario is plausible in general, it is unlikely in our case because local elites play no direct role in carrying out the audit. Auditors go into a municipality with specific orders to investigate particular programs and projects and the items on their list are not subject to local review. Neither is it likely that local managers succeed in systematically concealing irregular transactions such that auditors fail to uncover them since the audit is very thorough, involving both financial auditing and detailed inspection of public works and services.

\subsection{Municipality and mayor characteristics}

Data on municipality characteristics are obtained from several sources. Official local population data for the year 2007 are from the population count conducted by the Instituto Brasileiro de Geografia e Estatística (IBGE). Data on local income distribution and schooling are from the Instituto de Pesquisa Economica Aplicada (IPEA) based on the 2000 census. Mayor characteristics and party affiliations are from the Tribunal Superior Eleitoral (TSE). Table 7 gives difference in means tests for a host of pre-treatment covariates. With the exception of one party affiliation dummy, none of these differences are statistically significant and the magnitudes are generally small. Table 7 also provides a joint test of the null hypotheses that the population means of these covariates are equal across treatment and control groups. The F-statistic suggests that the randomization worked, that is, it fails to reject the null at conventional levels of significance $(\mathrm{p}$-value $=0.44)$. 


\section{Estimation results}

Table 8 presents OLS estimates from equation 1 for the proportion of non-competitive procurement modalities at the municipality level. Columns 1 through 5 are based solely on the 32nd lottery and provide the raw difference in means and estimates with state intercepts, mayor party affiliation dummies, municipality characteristics, and mayor's characteristics, respectively. Columns 6 through 10 show estimates from the same five specifications but for the pooled sample, including control municipalities from the 31st lottery. Treatment effect estimates fluctuate around the -0.12 mark across specifications and across the $32 \mathrm{nd}$ and pooled estimation samples. This suggests both that the randomization worked and that outcomes do not systematically vary from one year to the next. Due to the doubling of the sample size, estimates become statistically significant at $5 \%$ in the pooled sample, even before adding any controls. Given that the control group mean proportion of non-competitive procurement processes is 0.70 , the effect corresponds to a $17 \%$ reduction approximately. ${ }^{26}$ Figure 2 shows that the difference in sample means is not driven by outliers but that the treatment rotated the entire distribution of non-competitive procurement processes to the left.

Table 9 presents impact estimates on the number of local procurement processes. Treatment effect estimates fluctuate around -3 to -4 processes and are statistically significant at $10 \%$ throughout and at 5\% in the pooled sample, again even before adding control variables. Given that the control group mean number of processes is about 14 , the effect corresponds to a $20 \%$ to $30 \%$ reduction approximately. As with the proportion of non-competitive procurement modalities above, Figure 3 shows that the treatment rotated the entire distribution of the number of procurement processes to the left. The reduction in the number of procurements is entirely driven by fewer non-competitive modalities (results omitted to save space). This result is consistent with the previous finding on procurement modalities since a typical way of circumventing more competitive procedures, such as a sealed-bid (reverse) auction, is to fractionalize the purchase (break it up into pieces) and conduct a series of less competitive procurement processes, such

\footnotetext{
${ }^{26}$ When we add state intercepts, mayor's party affiliation dummies, municipality characteristics, mayor's characteristics or a combination of these sets of covariates jointly, estimates of the treatment effect remain in the range shown in the table. Standard errors remain largely unchanged because higher explained variance and fewer degrees of freedom tend to cancel each other out. These additional robustness checks are available on request.
} 
as "bids only by invitation".

Another potential explanation for the reduction in non-competitive procurement processes is that local managers were actually doing less procurement, not just different modalities, perhaps in order to "sit out" the high audit risk year. From an empirical perspective, however, there is no evidence that treatment group municipalities were spending less transfers from the central government during 2009 (results available on request). This zero effect on spending makes sense from a practical point of view as well since for many goods, such as staple foods, medications or contracted-out cleaning services, local governments hold few or no inventories at all and so they need to make purchases to keep the administration running. Moreover, federal funds typically must be used during the fiscal year or else returned to the federal government, they cannot be saved for later periods. So, not doing a procurement at all for an entire year is not an attractive option for local officials.

Table 10 presents estimates of the impact on the proportion of irregular procurement processes. A process is deemed irregular if the audit result from Table 6 is anything other than regular. Treatment effect estimates fluctuate around the -0.14 mark, are statistically significant at $10 \%$ in the sample from the 32nd lottery, and become statistically significant at 5\% in the pooled sample, again even without controls. Given that the control group mean proportion of irregular processes is again 0.70 , the effect corresponds to a $20 \%$ reduction approximately. Figure 4 shows that the treatment shifted the entire distribution of the proportion of irregular procurement processes to the left.

The top part of Table 11 presents impact estimates for a range of outcomes related to the preventive and basic health care program (Saúde da Familia). In contrast to the effects found for procurement, Table 11 shows no evidence that increased audit risk affected the quality of health care services provided by local governments. For example, the average share of respondents who say they receive regular visits from community health staff-as required under the preventive health program - is essentially $93 \%$ in both treatment and control groups. The proportion of respondents who say they receive health care at home when needed is about $70 \%$ in the control group and about $80 \%$ in the treatment group, but the difference is not statistically 
significant.

Overall, out of the eleven outcomes considered here, none are statistically different between treatment and control groups. Moreover, the size of the differences is typically small and often the sign of the difference is the opposite of what theory would suggest. Since potential punishments for serious irregularities in procurement include jail, while for service delivery they only include fines or loss of the job, differences in potential punishments might drive the difference in results. A complementary interpretation is that irregularities in service provision cannot be identified with the same precision as irregularities in procurement and so higher audit risk might matter less to service providers, compared to procurement officials. For example, while health facility users might complain about infrequent opening hours of the health post, health staffers could easily dispute this fact and auditors would have a hard time verifying any of these competing claims. ${ }^{27}$

The bottom of Table 11 shows that higher audit risk did not seem to affect local compliance with national guidelines of the conditional cash transfer program Bolsa Familia either. The first two outcomes show that targeting of beneficiaries was unaffected since the proportion of appropriately included beneficiaries is negligibly (and statistically insignificantly) different between treatment and control respondents. The last three outcomes show the same qualitative result for compliance with health and education conditionalities. Again, differences in punishment are likely to be part of the explanation for the zero effect since the punishment for overstating the number of kids in the household or for not sending them to school, for example, is at most the loss of the benefit. Another interpretation, which is supported by the high compliance rate evident in Table 11, is that most Bolsa Familia recipients were appropriately included in the program - they were poor enough - and they already complied with health and education conditionalities to a large extent. Thus, they could not respond to higher audit risk because they were doing nothing wrong in the first place.

\footnotetext{
${ }^{27}$ Another interpretation is that there simply was not that much shirking on the job going on in preventive and basic health care delivery. We consider this possibility less likely since substantial numbers of health service users in our data do in fact indicate that health posts are not always open exactly as required by ministry of health regulations.
} 


\section{Conclusion}

This paper provides experimental evidence that increasing audit risk by about 20 percentage points reduced the proportion of non-competitive procurement modalities adopted by local managers by about 17 percent. Higher audit risk also reduced the proportion of local procurement processes involving waste or corruption by about 20 percent. As in Olken (2007), we cannot say whether these effects reflect a net reduction in rent extraction or merely a substitution over time-with treatment group municipalities "making up" at least some lost rents in subsequent periods. In either case, our estimates provide clear evidence in favor of the prediction that local officials reduce rent extraction in response to higher audit risk (Becker 1968).

In contrast, we find no evidence that increased audit risk affected the quality of preventive and primary health care services, measured using client satisfaction surveys conducted by auditors. Since potential punishments for serious irregularities in procurement include jail, while for service delivery they only include fines or loss of the job, differences in potential punishments might drive the difference in results. A complementary interpretation is that irregularities in service provision cannot be identified with the same precision as irregularities in procurement and so higher audit risk might matter less to service providers, compared to procurement officials.

We also find no evidence that higher audit risk had an effect on local compliance with national guidelines of the conditional cash transfer program Bolsa Familia, measured in terms of appropriate inclusion of beneficiaries into the program or their compliance with health and education conditionalities. Again, differences in punishment are likely to be part of the explanation for the zero effect since the punishment for overstating the number of kids in the household or for not sending them to school, for example, is at most the loss of the benefit. Another interpretation, which is supported by our data, is that most Bolsa Família recipients were appropriately included in the program - they were poor enough — and they already complied with health and education conditionalities to a large extent.

Audit intensity should be scaled up permanently if and only if the net benefits of such a policy are positive. Although the results from increasing audit risk temporarily are encouraging, it would take a permanent variation in audit risk to assess whether scaling up is indeed advisable, 
since local officials might find ways to adapt to increased audit risk over time. Another complication is that assessing the benefits of higher audit risk in monetary terms requires an estimate of the value of a marginal increase in compliance with existing procurement regulations. A necessary first step in this direction would be to quantify the cost savings from lower procurement costs. Unfortunately, however, audit findings currently do not systematically report the price at which local goods and services were purchased. More detailed data is therefore required to better quantify the benefits of higher audit intensity in terms of cost savings. 


\section{References}

Arantes, R. B., 2004, The Brazilian "Ministerio Publico" and political corruption in Brazil, Centre for Brazilian Studies, University of Oxford, Working Paper 50-04.

Bandiera O., A. Prat and T. Valletti, 2008, “Active and Passive Waste in Government Spending: Evidence from a Policy Experiment," American Economic Review, 99: 1278-1308.

Barro, R. J., 1973, “The Control of Politicians: An Economic Model,” Public Choice, 14: $19-42$.

Becker, G., 1968, “Crime and Punishment: An Economic Approach,” Journal of Political Economy, 76(2): 169-217.

Di Tella, R., and E. Schargrodsky, 2003, "The Role of Wages and Auditing During a Crackdown on Corruption in the City of Buenos Aires," Journal of Law and Economics, 46: $269-292$.

Ferraz, C. and F. Finan, 2010, "Electoral Accountability and Corruption: Evidence from the Audit Reports of Local Governments," American Economic Review, forthcoming.

Golden, M. A. and L. Picci, 2005, "Proposal for a New Measure of Corruption, Illustrated with Italian Data," Economics and Politics, 17, 37-75.

Litschig S. and Y. Zamboni, 2010, “Judicial Presence and Rent Extraction,” Universitat Pompeu Fabra Working Paper 1143.

Mookherjee D. and I.P.L.Png, 1995, "Corruptible Enforcers: How Should They Be Compensated?" The Economic Journal, 105: 145-159.

Olken, B. A., 2007, “Monitoring Corruption,” Journal of Political Economy, 115(2): 200-249.

Persson, T. and G. Tabellini, 2000, Political Economics: Explaining Economic Policy, Cambridge, MA, MIT Press.

Public Expenditure and Financial Accountability partnership program, 2006, Public Financial Management Performance Measurement Framework, Washington DC. 
Reinikka, R and J. Svensson, 2004, "Local Capture: Evidence from a Central Government Transfer Program in Uganda," Quarterly Journal of Economics, 2: 679-706.

Rose-Ackerman, S. 1999, Corruption and Government, Causes, Consequences and Reform, Cambridge University Press.

—, 2004, "Governance and Corruption," in Global Crises, Global Solutions, B. Lomborg, ed. Cambridge: Cambridge University Press, chapter 6. 
Table 1: Randomization lottery May 12th 2009

\begin{tabular}{|c|c|c|c|}
\hline & $\mathrm{N}$ & Draws & $\mathrm{P}($ Treatment $) \%$ \\
\hline Acre $(\mathrm{AC})$ & 21 & & 4.0 \\
\hline Amapá (AP) & 15 & 2 & 4.0 \\
\hline Roraima (RR) & 14 & & 4.0 \\
\hline Alagoas (AL) & 101 & 2 & 2.0 \\
\hline Amazonas (AM) & 61 & 2 & 3.3 \\
\hline Bahia (BA) & 415 & 10 & 2.4 \\
\hline Ceará (CE) & 183 & 6 & 3.3 \\
\hline Espírito Santo (ES) & 77 & 2 & 2.6 \\
\hline Goiás (GO) & 245 & 6 & 2.4 \\
\hline Maranhão (MA) & 216 & 6 & 2.8 \\
\hline Minas Gerais (MG) & 849 & 14 & 1.6 \\
\hline Mato Grosso do Sul (MS) & 77 & 2 & 2.6 \\
\hline Mato Grosso (MT) & 140 & 2 & 1.4 \\
\hline Pará (PA) & 142 & 4 & 2.8 \\
\hline Paraíba (PB) & 222 & 6 & 2.7 \\
\hline Pernambuco (PE) & 182 & 4 & 2.2 \\
\hline Piauí (PI) & 223 & 6 & 2.7 \\
\hline Paraná (PR) & 397 & 8 & 2.0 \\
\hline Rio de Janeiro (RJ) & 88 & 2 & 2.3 \\
\hline Rio Grande do Norte (RN) & 166 & 4 & 2.4 \\
\hline Rondônia (RO) & 51 & 2 & 3.9 \\
\hline Rio Grande do Sul (RS) & 495 & 10 & 2.0 \\
\hline Santa Catarina (SC) & 292 & 6 & 2.1 \\
\hline Sergipe (SE) & 74 & 2 & 2.7 \\
\hline São Paulo (SP) & 636 & 10 & 1.6 \\
\hline Tocantins (TO) & 138 & 2 & 1.4 \\
\hline Total & $5^{\prime} 520$ & 120 & \\
\hline
\end{tabular}

Source: Portaria N. ${ }^{\circ}$ 930, May 8th 2009. 
Table 2: 29th lottery August 17th 2009

\begin{tabular}{lccc}
\hline \hline & $\mathrm{N}$ & Draws & P(Draw) \% \\
\hline Acre (AC) & 18 & & 2.3 \\
Amapá (AP) & 12 & 1 & 2.3 \\
Roraima (RR) & 13 & & 2.3 \\
Alagoas (AL) & 82 & 2 & 2.4 \\
Amazonas (AM) & 53 & 1 & 1.9 \\
Bahia (BA) & 389 & 5 & 1.3 \\
Ceará (CE) & 166 & 3 & 1.8 \\
Espírito Santo (ES) & 71 & 1 & 1.4 \\
Goiás (GO) & 230 & 2 & 0.9 \\
Maranhão (MA) & 189 & 3 & 1.6 \\
Minas Gerais (MG) & 812 & 7 & 0.9 \\
Mato Grosso do Sul (MS) & 71 & 1 & 1.4 \\
Mato Grosso (MT) & 132 & 1 & 0.8 \\
Pará (PA) & 127 & 3 & 2.4 \\
Paraíba (PB) & 207 & 3 & 1.4 \\
Pernambuco (PE) & 159 & 3 & 1.9 \\
Piauí (PI) & 205 & 3 & 1.5 \\
Paraná (PR) & 378 & 3 & 0.8 \\
Rio de Janeiro (RJ) & 83 & 1 & 1.2 \\
Rio Grande do Norte (RN) & 153 & 3 & 2.0 \\
Rondônia (RO) & 46 & 1 & 2.2 \\
Rio Grande do Sul (RS) & 472 & 4 & 0.8 \\
Santa Catarina (SC) & 280 & 2 & 0.7 \\
Sergipe (SE) & 66 & 1 & 1.5 \\
São Paulo (SP) & 609 & 5 & 0.8 \\
Tocantins (TO) & 132 & 1 & 0.8 \\
\hline Total & $5 ' 155$ & 60 & \\
\hline \hline Sourc: Por & & & \\
\hline
\end{tabular}

Source: Portaria N. ${ }^{\circ} 1581$, August 11th 2009. 
Table 3: 32nd lottery May 10th 2010

\begin{tabular}{|c|c|c|c|c|c|c|c|c|c|}
\hline & \multicolumn{3}{|c|}{ Treatment Group } & \multicolumn{4}{|c|}{$\underline{\text { Control Group }}$} & \multirow{2}{*}{$\begin{array}{c}\text { Ex post } \\
\mathrm{dP} \\
\end{array}$} & \multirow{2}{*}{$\begin{array}{c}\text { Ex ante } \\
\mathrm{dP}\end{array}$} \\
\hline & $\mathrm{N}$ & Draws & $\mathrm{P}$ (Audit) & $\mathrm{N}$ & Draws & $\mathrm{P}($ Draw $)$ & $\mathrm{P}$ (Audit) & & \\
\hline Acre & 0 & \multirow{2}{*}{1} & 50.0 & 21 & \multirow{2}{*}{1} & 1.1 & 7.8 & 42.2 & 17.2 \\
\hline Mato Grosso do Sul & 2 & & 50.0 & 72 & & 1.1 & 5.2 & 44.8 & 19.8 \\
\hline Alagoas & 2 & \multirow{2}{*}{1} & 25.0 & 92 & \multirow{2}{*}{1} & 0.6 & 7.7 & 17.3 & 17.3 \\
\hline Sergipe & 2 & & 25.0 & 66 & & 0.6 & 5.1 & 19.9 & 19.9 \\
\hline Amazonas & 2 & \multirow{2}{*}{1} & 25.0 & 56 & \multirow{2}{*}{1} & 1.0 & 6.5 & 18.5 & 18.5 \\
\hline Rondônia & 2 & & 25.0 & 46 & & 1.0 & 7.3 & 17.7 & 17.7 \\
\hline Amapá & 1 & \multirow{2}{*}{1} & 50.0 & 12 & \multirow{2}{*}{1} & 4.3 & 10.9 & 39.1 & 14.1 \\
\hline Roraima & 1 & & 50.0 & 11 & & 4.3 & 10.9 & 39.1 & 14.1 \\
\hline Espírito Santo & 2 & \multirow{2}{*}{1} & 25.0 & 72 & \multirow{2}{*}{1} & 0.7 & 4.8 & 20.2 & 20.2 \\
\hline Rio de Janeiro & 2 & & 25.0 & 80 & & 0.7 & 4.2 & 20.8 & 20.8 \\
\hline Bahia & 10 & 2 & 20.0 & 385 & 2 & 0.5 & 4.3 & 15.7 & 20.7 \\
\hline Ceará & 6 & 1 & 16.7 & 162 & 1 & 0.6 & 5.9 & 10.8 & 19.1 \\
\hline Goiás & 6 & 1 & 16.7 & 230 & 1 & 0.4 & 3.0 & 13.7 & 22.0 \\
\hline Maranhão & 6 & 1 & 16.7 & 200 & 1 & 0.5 & 5.2 & 11.5 & 19.8 \\
\hline Minas Gerais & 14 & 4 & 28.6 & 813 & 4 & 0.5 & 3.0 & 25.5 & 22.0 \\
\hline Mato Grosso & 2 & 1 & 50.0 & 131 & 1 & 0.8 & 4.9 & 45.1 & 20.1 \\
\hline Pará & 4 & 1 & 25.0 & 125 & 1 & 0.8 & 7.7 & 17.3 & 17.3 \\
\hline Paraíba & 6 & 1 & 16.7 & 206 & 1 & 0.5 & 4.7 & 11.9 & 20.3 \\
\hline Pernambuco & 4 & 1 & 25.0 & 168 & 1 & 0.6 & 6.1 & 18.9 & 18.9 \\
\hline Piauí & 6 & 1 & 16.7 & 200 & 1 & 0.5 & 4.8 & 11.9 & 20.2 \\
\hline Paraná & 8 & 2 & 25.0 & 379 & 2 & 0.5 & 2.9 & 22.1 & 22.1 \\
\hline Rio Grande do Norte & 4 & 1 & 25.0 & 153 & 1 & 0.7 & 0.7 & 24.3 & 24.3 \\
\hline Rio Grande do Sul & 10 & 2 & 20.0 & 472 & 2 & 0.4 & 2.9 & 17.1 & 22.1 \\
\hline Santa Catarina & 6 & 2 & 33.3 & 280 & 2 & 0.7 & 2.8 & 30.5 & 22.2 \\
\hline São Paulo & 10 & 3 & 30.0 & 610 & 3 & 0.5 & 2.9 & 27.1 & 22.1 \\
\hline Tocantins & 2 & 1 & 50.0 & 133 & 1 & 0.8 & 3.0 & 47.0 & 22.0 \\
\hline Total & 120 & 30 & & $\overline{5^{\prime} 175}$ & 30 & & & & \\
\hline
\end{tabular}

Source: Portaria N. ${ }^{\circ}$ 862, April 30th 2010. P(Draw), P(Audit) and dP are given as percentages. For the treatment group, the probability of being drawn in the 32nd lottery equals the probability of receiving a CGU audit between May 2009 and May 2010, P(Draw)=P(Audit). Ex ante (From May 8th 2009 to the publication of Portaria N. 862 on April 30th 2010) this probability was $30 / 120=25 \%$. Ex post, it is given above in column 3 . For the control group, the probability of receiving a CGU audit between May 2009 and May 2010 depends on the probabilities of being drawn in the 29th, 30th, 31st and 32nd lotteries. P(Audit) for the control group is therefore calculated according to the following approximation: $\mathrm{P}($ Audit $)=1-[1-\mathrm{P}(\mathrm{Draw}$ 29 th $)]^{\wedge} 3 \times[1-\mathrm{P}($ Draw 32 th $)]$. dP gives the ex ante and ex post difference in audit probabilities between treatment and control groups by state. 


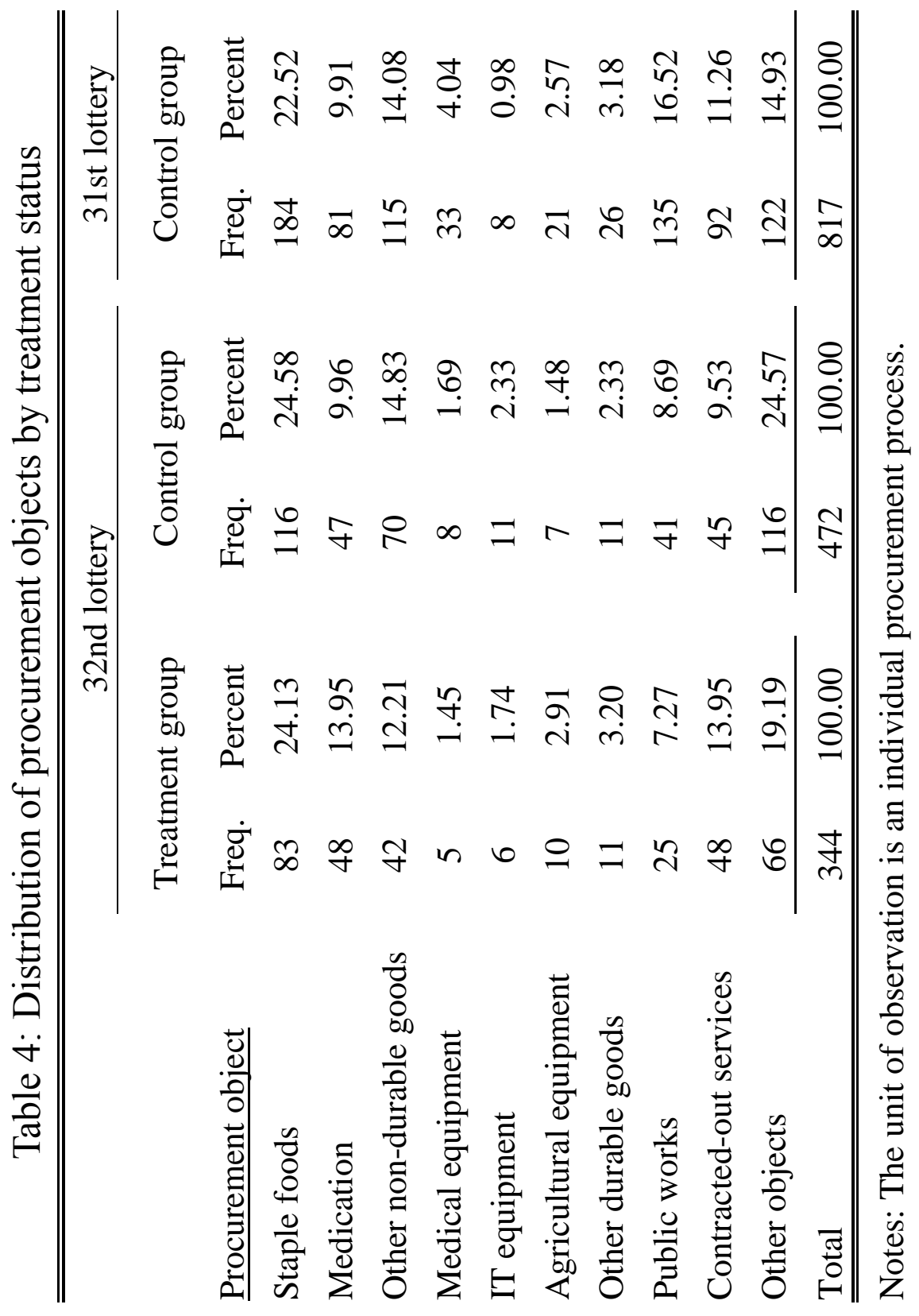




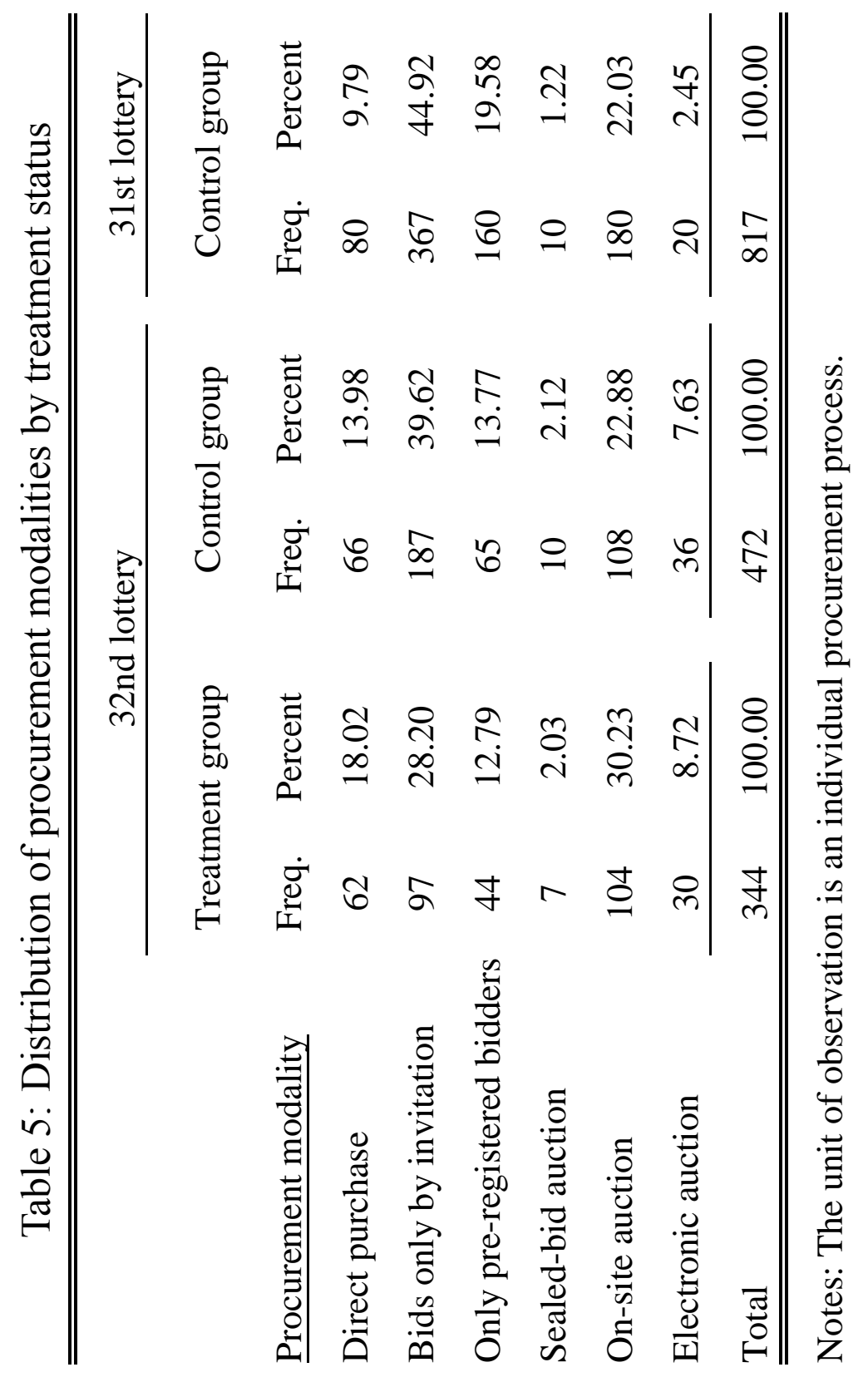




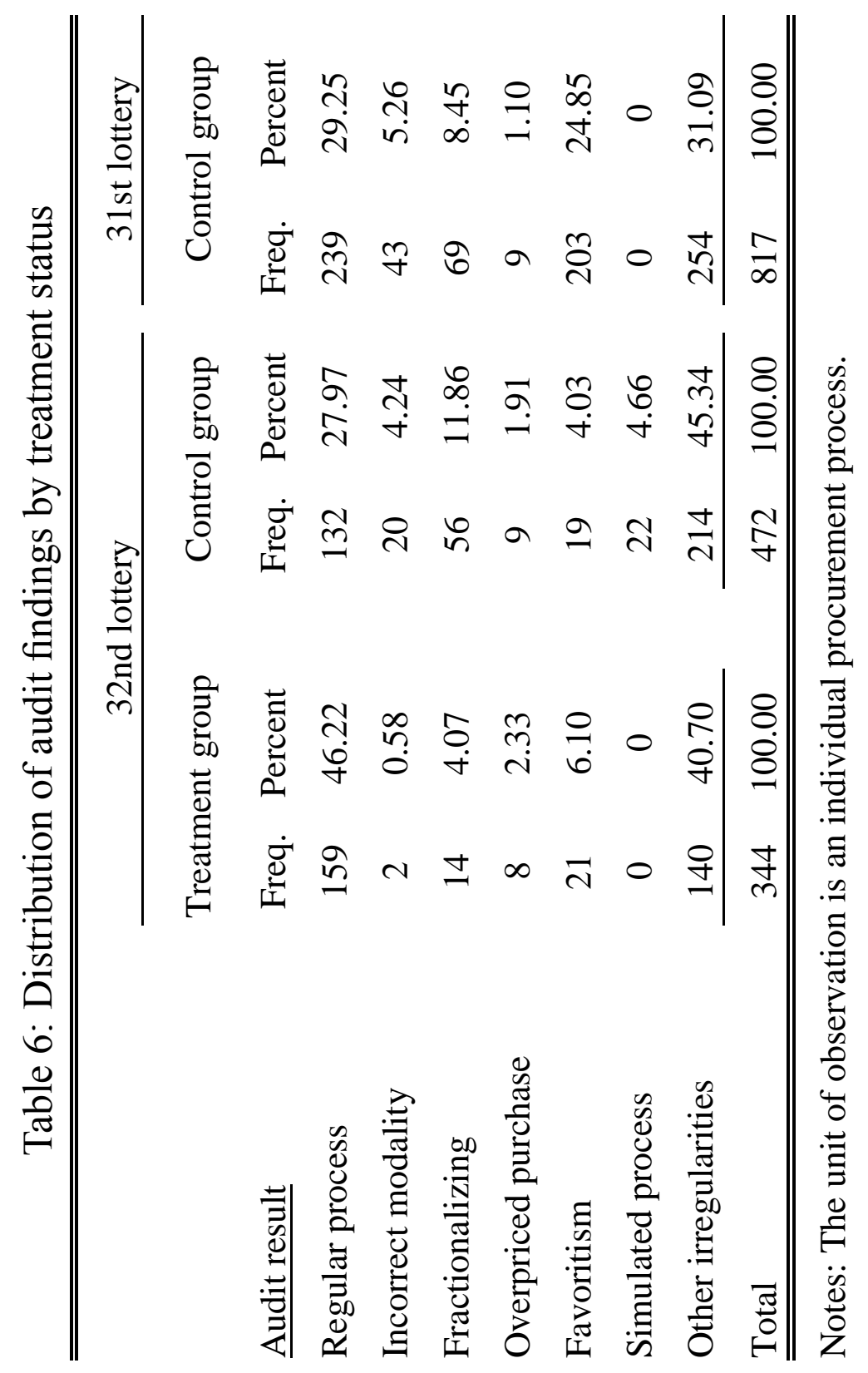


Table 7: Difference in means tests for pre-treatment covariates

\begin{tabular}{|c|c|c|c|c|}
\hline & Treatment group & Control group & Difference & P-value \\
\hline Population & $\begin{array}{l}21 ' 512 \\
(6 ' 822)\end{array}$ & $\begin{array}{c}18 ' 653 \\
(2 ' 580)\end{array}$ & $\begin{array}{c}2 ' 858 \\
\left(7^{\prime} 294\right)\end{array}$ & 0.69 \\
\hline Income per capita & $\begin{array}{l}162.5 \\
(15.6)\end{array}$ & $\begin{array}{c}157 \\
(8.5)\end{array}$ & $\begin{array}{c}5.5 \\
(17.8)\end{array}$ & 0.76 \\
\hline Average years of schooling & $\begin{array}{c}3.86 \\
(0.25)\end{array}$ & $\begin{array}{c}3.89 \\
(0.12)\end{array}$ & $\begin{array}{l}-0.03 \\
(0.27)\end{array}$ & 0.88 \\
\hline Urbanization & $\begin{array}{c}0.57 \\
(0.04)\end{array}$ & $\begin{array}{c}0.59 \\
(0.02)\end{array}$ & $\begin{array}{l}-0.02 \\
(0.05)\end{array}$ & 0.62 \\
\hline Poverty headcount ratio & $\begin{array}{c}0.26 \\
(0.04)\end{array}$ & $\begin{array}{c}0.26 \\
(0.02)\end{array}$ & $\begin{array}{c}0.00 \\
(0.04)\end{array}$ & 0.97 \\
\hline Poverty gap & $\begin{array}{c}0.52 \\
(0.04)\end{array}$ & $\begin{array}{c}0.49 \\
(0.02)\end{array}$ & $\begin{array}{c}0.03 \\
(0.02)\end{array}$ & 0.18 \\
\hline Gini coefficient & $\begin{array}{c}0.56 \\
(0.01)\end{array}$ & $\begin{array}{c}0.56 \\
(0.00)\end{array}$ & $\begin{array}{c}0.00 \\
(0.01)\end{array}$ & 0.76 \\
\hline Radio station & $\begin{array}{c}0.46 \\
(0.09)\end{array}$ & $\begin{array}{c}0.45 \\
(0.05)\end{array}$ & $\begin{array}{c}0.01 \\
(0.05)\end{array}$ & 0.62 \\
\hline PMDB & $\begin{array}{c}0.20 \\
(0.07)\end{array}$ & $\begin{array}{c}0.25 \\
(0.05)\end{array}$ & $\begin{array}{l}-0.05 \\
(0.09)\end{array}$ & 0.52 \\
\hline PSDB & $\begin{array}{c}0.13 \\
(0.06)\end{array}$ & $\begin{array}{c}0.17 \\
(0.04)\end{array}$ & $\begin{array}{c}-0.04 \\
(0.07)\end{array}$ & 0.56 \\
\hline PTB & $\begin{array}{c}0.03 \\
(0.03)\end{array}$ & $\begin{array}{c}0.10 \\
(0.03)\end{array}$ & $\begin{array}{l}-0.07 \\
(0.05)\end{array}$ & 0.15 \\
\hline PT & $\begin{array}{c}0.10 \\
(0.06)\end{array}$ & $\begin{array}{c}0.09 \\
(0.03)\end{array}$ & $\begin{array}{c}0.01 \\
(0.06)\end{array}$ & 0.86 \\
\hline PSB & $\begin{array}{c}0.10 \\
(0.06)\end{array}$ & $\begin{array}{c}0.08 \\
(0.03)\end{array}$ & $\begin{array}{c}0.02 \\
(0.06)\end{array}$ & 0.72 \\
\hline PR & $\begin{array}{c}0.10 \\
(0.06)\end{array}$ & $\begin{array}{c}0.08 \\
(0.03)\end{array}$ & $\begin{array}{c}0.02 \\
(0.06)\end{array}$ & 0.72 \\
\hline PP & $\begin{array}{c}0.16 \\
(0.07)\end{array}$ & $\begin{array}{c}0.03 \\
(0.02)\end{array}$ & $\begin{array}{c}0.13 \\
(0.07)\end{array}$ & 0.07 \\
\hline PDT & $\begin{array}{c}0.06 \\
(0.05)\end{array}$ & $\begin{array}{c}0.02 \\
(0.02)\end{array}$ & $\begin{array}{c}0.04 \\
(0.05)\end{array}$ & 0.37 \\
\hline \multicolumn{4}{|c|}{$\begin{array}{l}\text { F-statistic for the joint hypotheses that all differences are zero } \\
\text { (p-value) }\end{array}$} & $\begin{array}{l}1.02 \\
(0.44)\end{array}$ \\
\hline $\mathrm{N}$ & 30 & 90 & & \\
\hline
\end{tabular}

Notes: The first three columns give sample means, the difference in means and (standard errors). Municipality characteristics are from the 2000 census, except population, which is from the 2007 population count. Mayor's party affiliation is for the 2009-2012 term. 


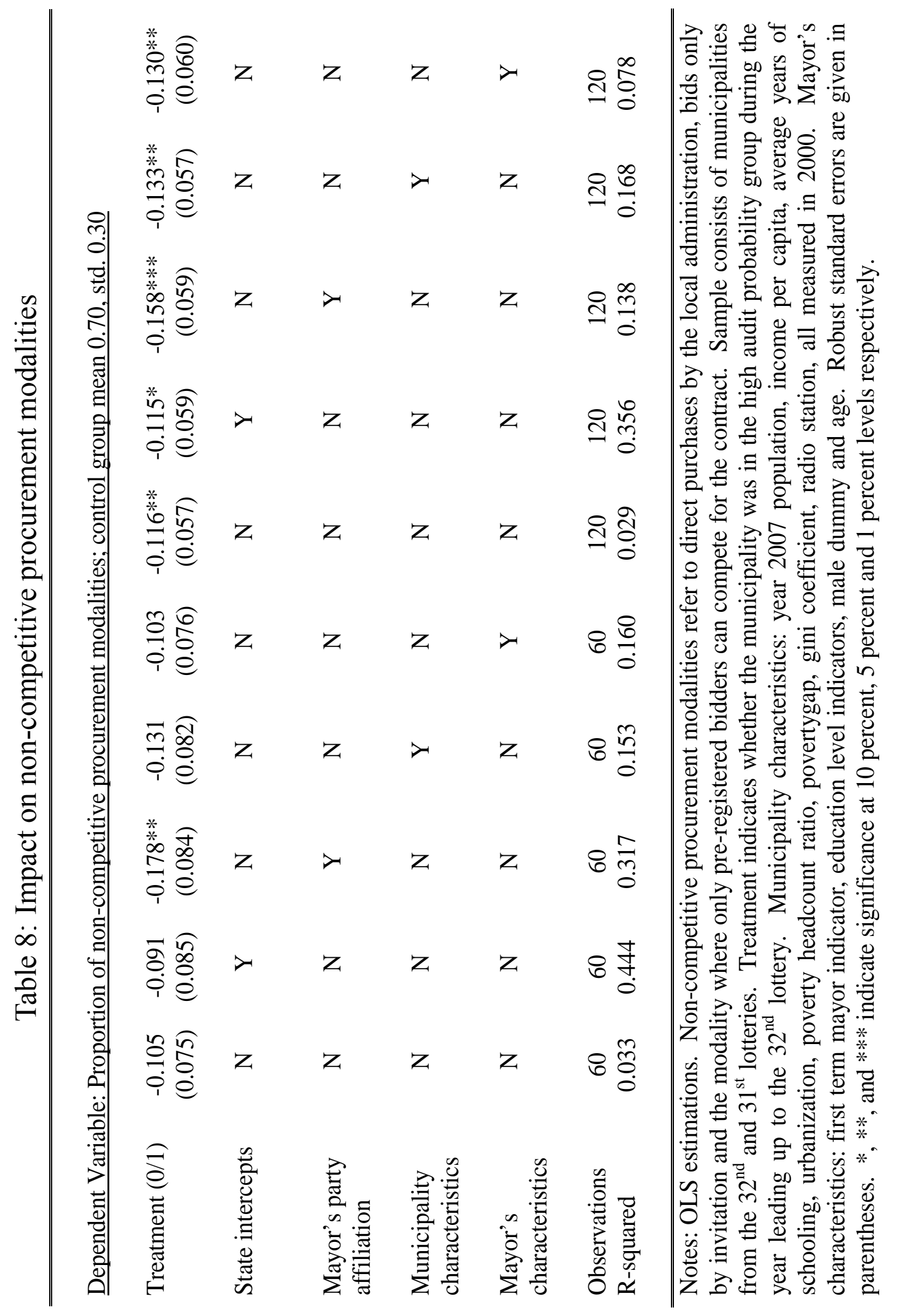




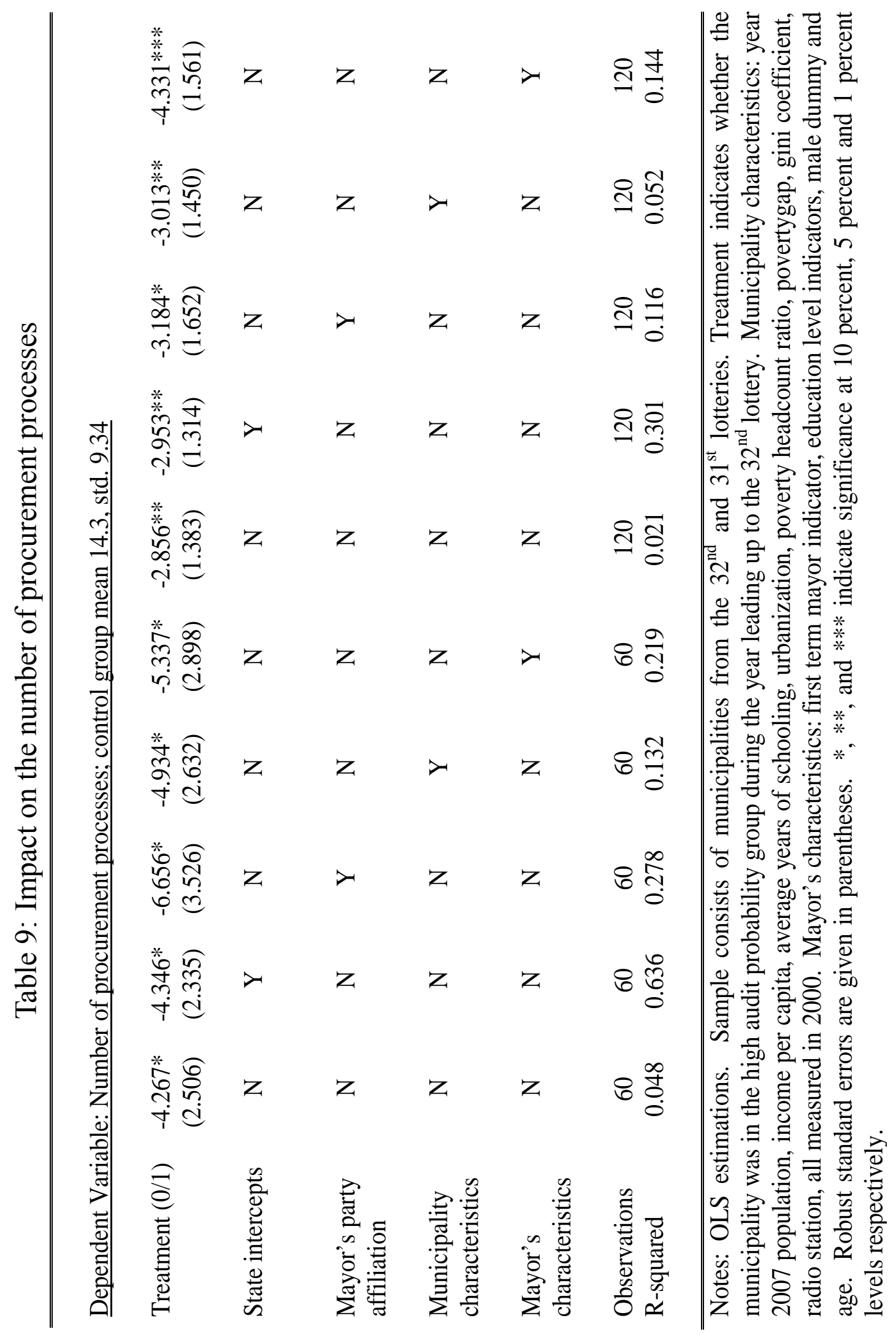




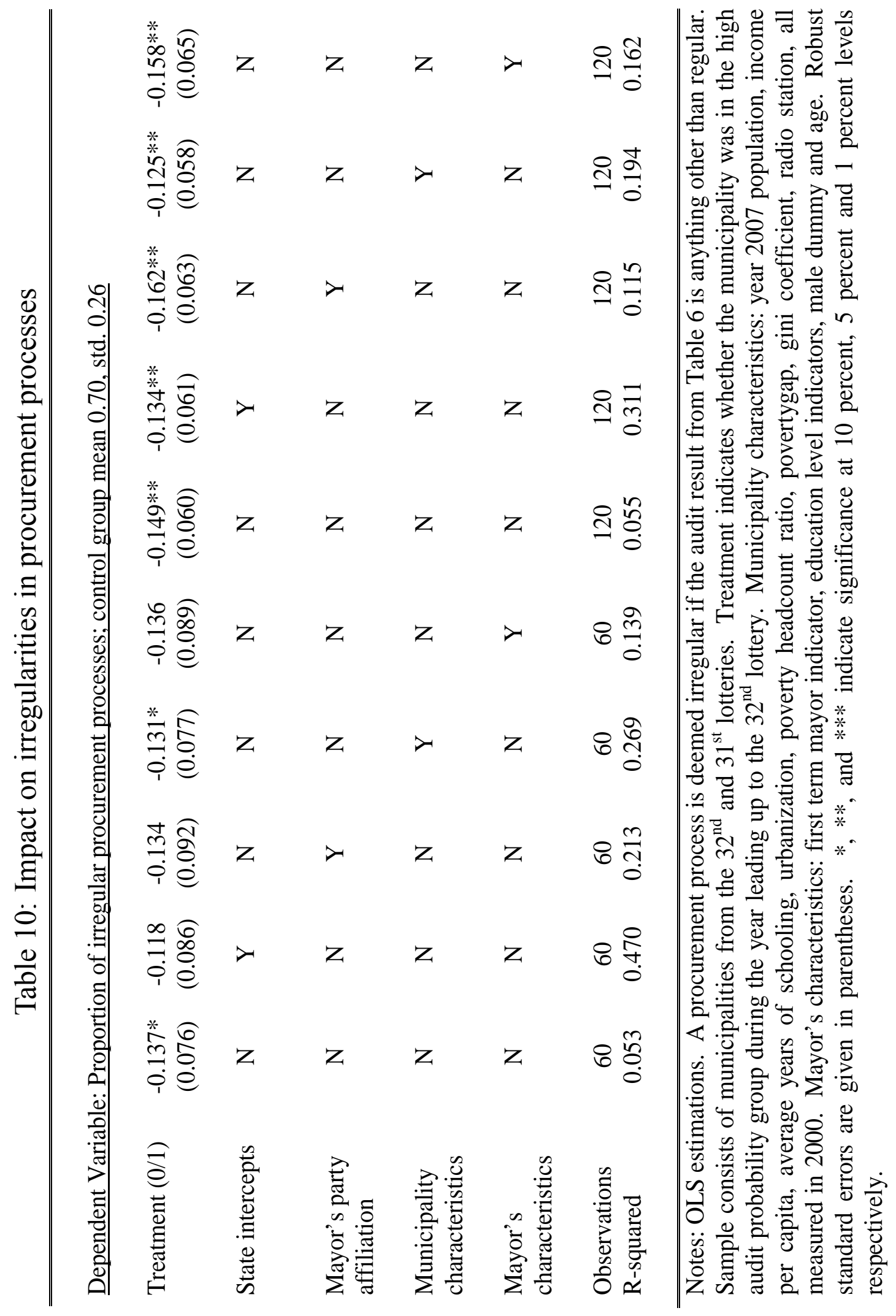


Table 11: Effects on health and conditional cash transfer programs

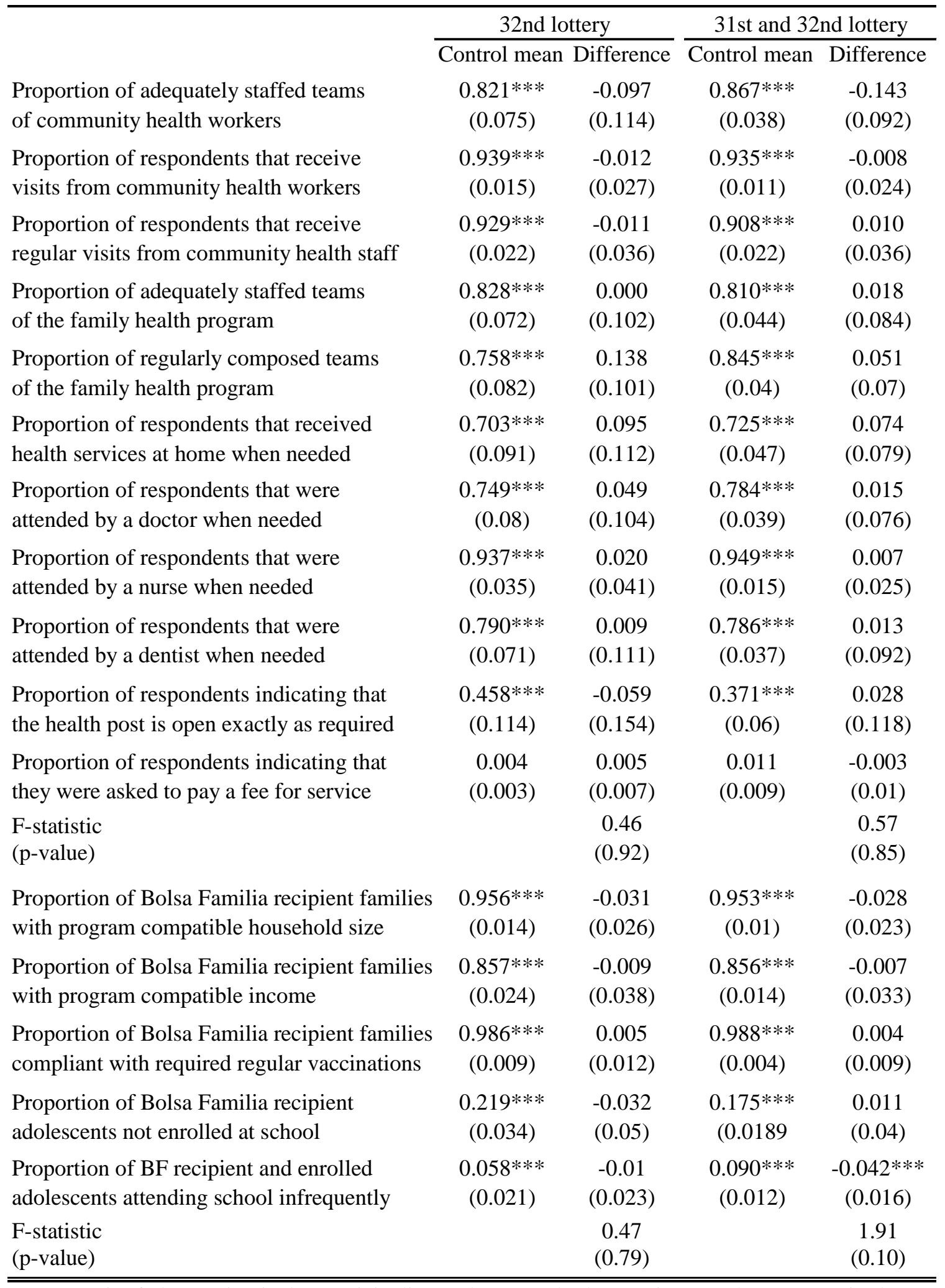

Notes: Unit of observation is the municipality. Robust standard errors in parentheses. $\mathrm{N}$ varies by outcome. F-statistic for the joint hypotheses that all differences in outcomes are zero. 

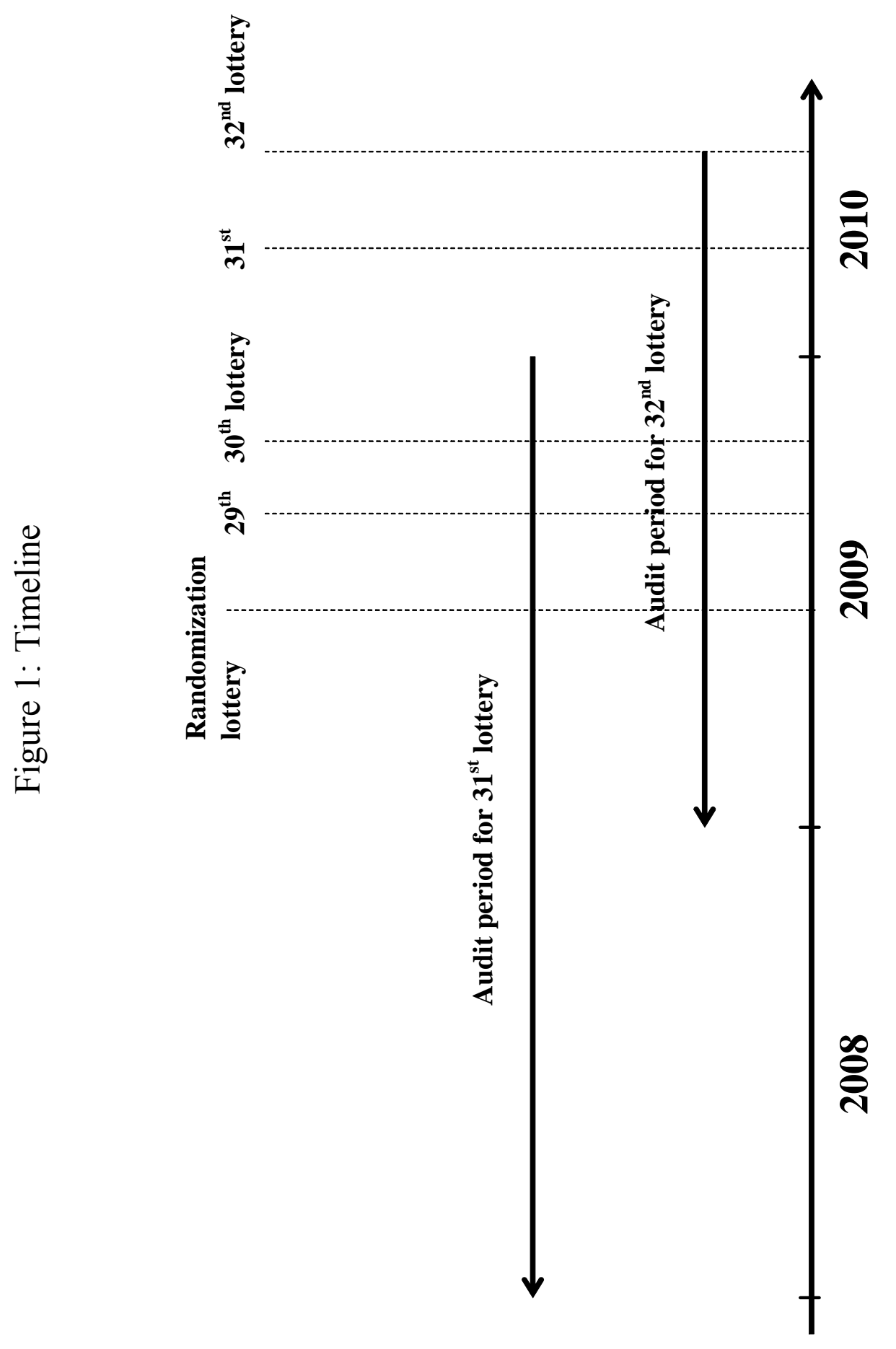


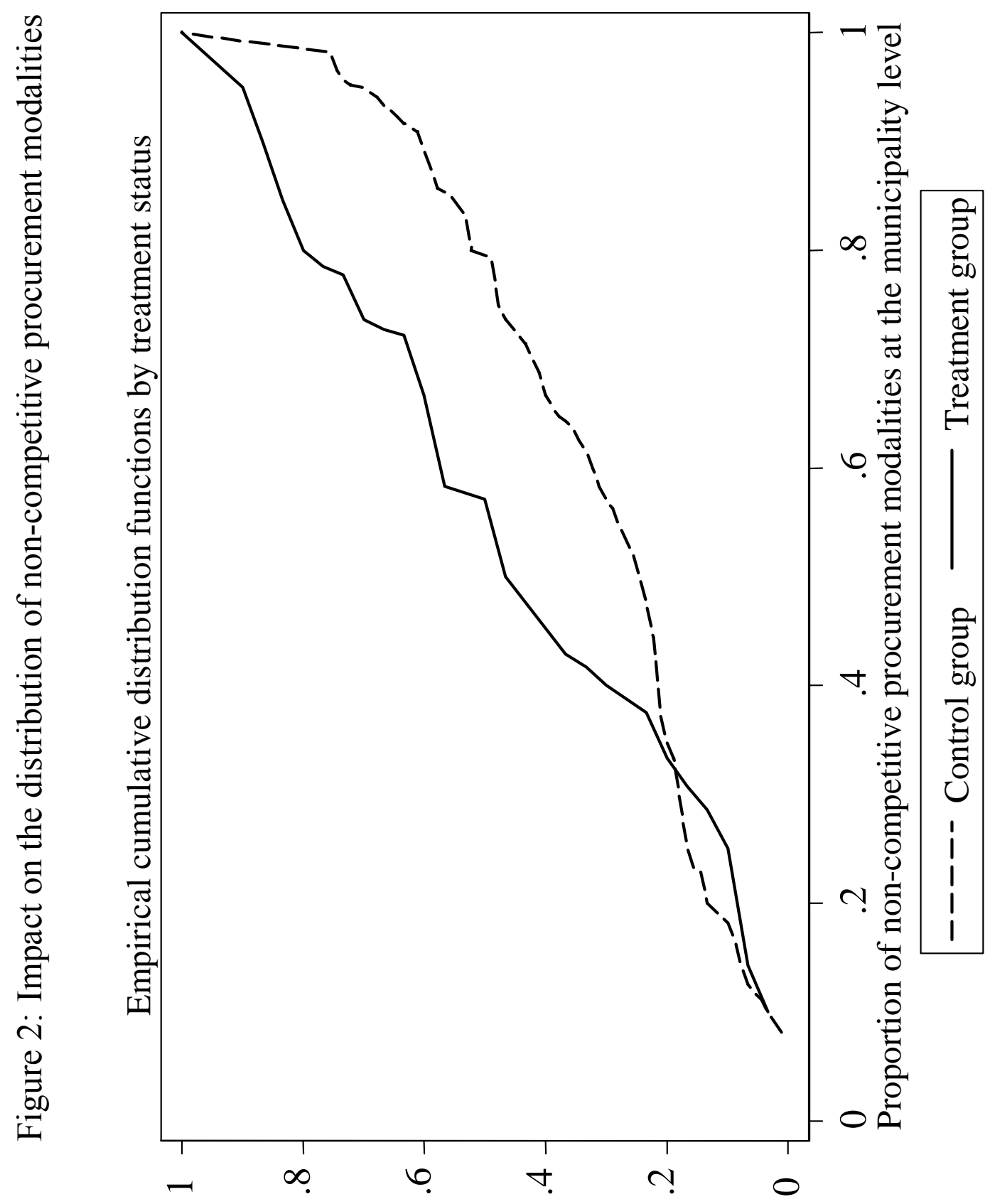




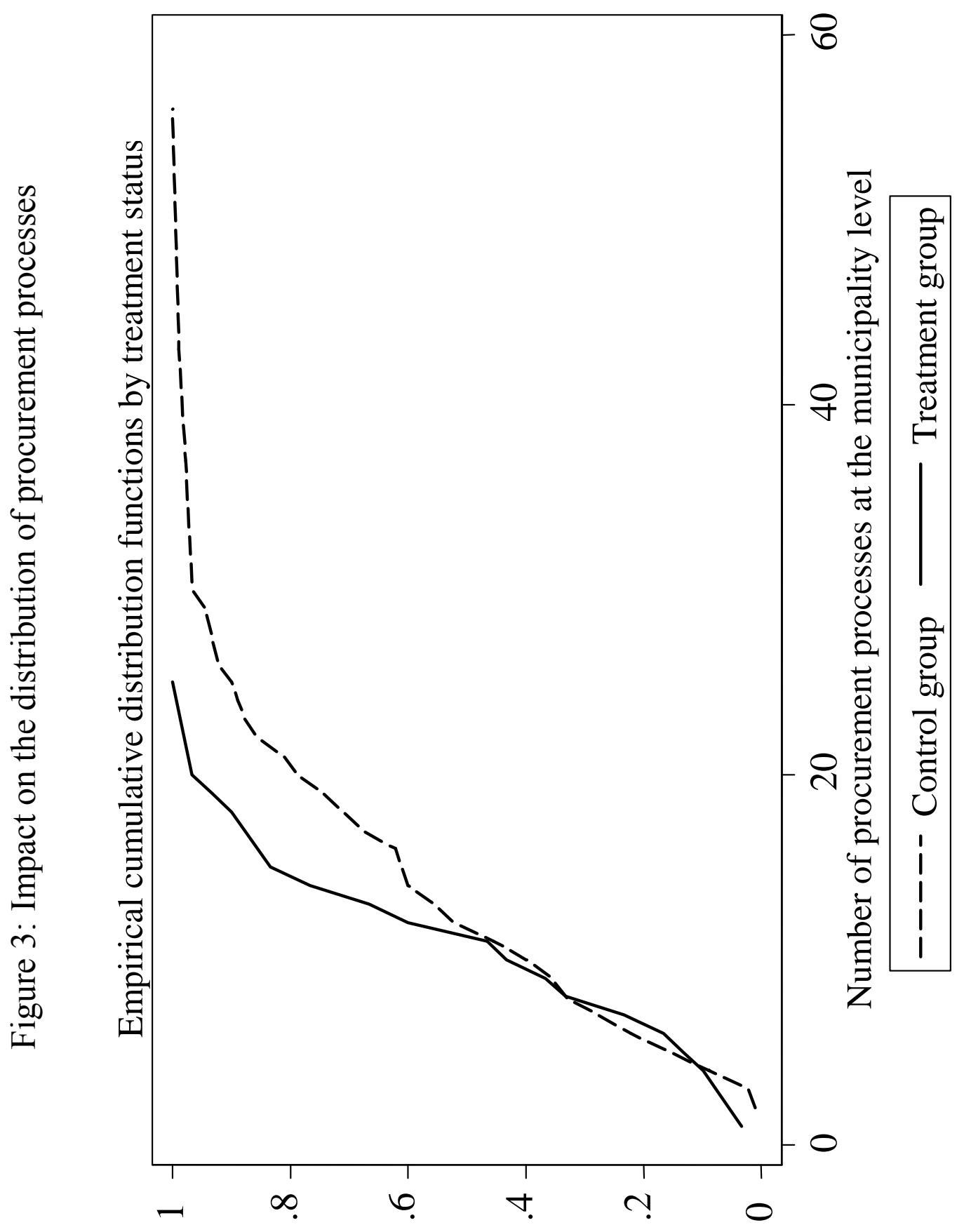






